\title{
Cervical Mixed Epithelial and Mesenchymal Neoplasm
}

National Cancer Institute

\section{Source}

National Cancer Institute. Cervical Mixed Epithelial and Mesenchymal Neoplasm. NCI

Thesaurus. Code C40226.

A benign or malignant neoplasm that arises from the cervix and is characterized by the presence of epithelial and mesenchymal elements. This category includes adenofibroma, adenomyoma, adenosarcoma, and carcinosarcoma. 